\title{
Systematic Literature Review of Clinical and Economic Outcomes of Micro-Invasive Glaucoma Surgery (MIGS) in Primary Open-Angle Glaucoma
}

Pavi Agrawal $\cdot$ Steven E. Bradshaw

Received: March 12, 2018 / Published online: May 3, 2018

(C) The Author(s) 2018 clinical outcomes, randomized clinical trials (RCTs) comparing MIGS with trabeculectomy or other therapies, observational studies, and other non-RCTs were included. Clinical outcomes reviewed were the change from baseline in mean IOP levels and change in topical glaucoma medication. Safety was assessed by reported harm and adverse events. For economic evidence, trials on cost-effectiveness, cost-utility, cost-benefit, cost-consequences, cost-minimization, cost of illness, and specific procedure costs were included. Risk of bias was assessed for clinical studies using the Cochrane Risk of Bias tool.

Results: A total of nine RCTs (seven iStents ${ }^{\circledR}$, one Hydrus ${ }^{\circledR}$, and one CyPass $\left.^{\circledR}\right)$, seven nonRCTs (three iStent ${ }^{\circledR}$, three CyPass ${ }^{\circledR}$, and one Hydrus $^{\circledR}$ ), and 23 economic studies were analyzed. While various forms of trabeculectomy can achieve postoperative IOP of between 11.0 and $13.0 \mathrm{mmHg}$, MIGS devices described in this review were typically associated with higher postoperative IOP levels. In addition, MIGS devices may result in increased hypotony rates or bleb needling in subconjunctival placed devices, requiring additional medical resources to manage. There is limited available evidence on the cost-effectiveness of MIGS and therefore it remains unclear whether the cost of using MIGS is outweighed by cost savings through decreased medication and need for further interventions. 
Conclusion: Larger randomized trials and realworld observational studies are needed for MIGS devices to better assess clinical and economic effectiveness. Given the shortage of published data and increasing use of such procedures, living systematic reviews may help to provide ongoing and timely evidence-based direction for clinicians and decision makers. This review highlights the current unmet need for treatments that are easy to implement and reduce long-term IOP levels without increasing postoperative aftercare and cost.

Funding: Santen $\mathrm{GmbH}$, Germany.

Keywords: CyPass; Hydrus; Intraocular pressure (IOP); iStent; Micro-invasive; MIGS; Open-angle glaucoma; Trabeculectomy; XEN

\section{INTRODUCTION}

Glaucoma is the leading global cause of irreversible blindness. It is estimated that 44.1 million people, or $3 \%$ of the population aged between 40 and 80 years, have primary openangle glaucoma (POAG) [1]. The incidence of POAG is expected to rise to 65.5 million in 2020 because of an aging population [2]. POAG, a progressive ophthalmic disease which causes damage to the optic nerve and nerve fiber layer resulting in visual field and acuity loss [3, 4], can be caused by either elevated intraocular pressure (IOP; IOP-related) or alternative mechanisms (non-IOP-related) [5, 6]. In the IOP-related pathway, treatment requires a decrease in IOP achieved through various methods including topical ocular hypotensive treatments, laser trabeculoplasty, and invasive surgical management [7].

Topical ocular hypotensive medication can delay or prevent POAG in patients with elevated IOP [8]; however, patient adherence and ocular surface toxicity are major issues with medical management [9]. When topical medications or other interventions (such as laser) do not adequately reduce IOP, incisional surgery (trabeculectomy) is considered. Although trabeculectomy is considered the gold standard in the surgical management of glaucoma, it is a technically complex procedure that can result in failure due to scarring, decreased quality of life due to bleb-related foreign body sensation, induced astigmatism, and secondary cataracts [10]. Apart from incisional surgery and topical medication, various devices have been developed for the treatment of POAG including tubebased Molteno, Baerveldt, and Ahmed implants [11-13]. However, the failure rate of these is approximately $50 \%$ after 5 years [14], and the rate of re-operation in both trabeculectomy and tube-based devices is relatively high, at $29 \%$ and $9 \%$, respectively [15]. Consequently, there have been further developments in the biomaterials, shape, and drainage technique in newer devices, collectively referred to as micro-invasive glaucoma surgeries (MIGS); available MIGS include the iStent ${ }^{\circledR}$ [16], Hydrus Micro-Stent ${ }^{\circledR}$ [17], CyPass Micro-Stent ${ }^{\circledR}$ [18], and XEN $^{\circledR}$ (XEN gel stent) [19].

The main mechanisms by which IOP is lowered with MIGS devices include increasing trabecular outflow by bypassing the trabecular meshwork, increasing uveoscleral outflow via suprachoroidal pathways, or creating a subconjunctival drainage pathway [20]. These devices aim to provide a safer and less invasive means of achieving IOP reduction compared with traditional surgery. However, the clinical efficacy as measured by IOP reduction tends to be less pronounced; hence, to date MIGS are currently targeted at patients with mild to moderate glaucoma [21].

In addition, there is an economic burden of glaucoma attributable to ocular hypotensive medications, health care consultations, and glaucoma-related procedures (e.g., trabeculectomy, laser surgery, combined cataract/glaucoma surgery), and direct medical costs generally increase with glaucoma severity [22].

Since the launch of MIGS devices, as of December 2016 (the date of this literature review), little evidence had been summarized on their clinical and economic outcomes. Our full literature study also studied clinical and economic outcomes from device-augmented trabeculectomy using EX-PRESS ${ }^{\circledR}$ shunts. However, the aim of this present paper is to share findings on the analysis set of clinical outcomes and safety of commercially available MIGS devices compared with trabeculectomy, and 
findings for EX-PRESS-augmented incisional procedures (which are not classified as MIGS) have been excluded from the results presented herein. Economic outcomes are also reviewed to assess the positioning of MIGS devices in POAG treatment.

\section{METHODS}

\section{Search Methods for Identifying Studies}

The systematic literature review was conducted in accordance with National Institute for Health and Care Excellence (NICE) requirements for the Medical Technology Evaluation Programme [23]. Searches for clinical and economic outcomes were carried out in MEDLINE, EMBASE, and the Cochrane Library (CENTRAL and Cochrane Database of Systematic Reviews). Additional searches for economic evidence were carried out in the National Health Service Economic Evaluation Database (NHS EED) and National Institute of Health Research Health Technology Assessment (NIHR-HTA) database. Trials published in English between 2005 and 2016 were included using specific search terms for each of the databases, as detailed in supplementary online material Table 1.

\section{Ethics Statement}

This article is based on previously conducted studies and does not contain any studies with human participants or animals performed by any of the authors.

\section{Eligibility Criteria}

Studies included in the analysis were based on PICO inclusion criteria. Specifically, a population of adults at least 18 years old with POAG, an intervention of MIGS in at least one treatment arm vs any other glaucoma treatment, inclusion of all comparators, and primary outcomes of (1) IOP reduction (absolute or relative) and (2) mean reduction in ocular medicated drops, and secondary outcomes of (3) visual prognosis and (4) quality of life. For the clinical outcomes and effectiveness, randomized clinical trials (RCTs) comparing MIGS (e.g., iStent ${ }^{\circledR}$, CyPass $^{\circledR}$, Hydrus $^{\circledR}$, and XEN $\left.{ }^{\circledR}\right)$ and non-MIGS procedures specifically using EX-PRESS ${ }^{\circledR}$, with trabeculectomy (or other therapies), as well as observational studies or other non-RCTs were included in the full analysis set. For economic evidence, trials on cost-effectiveness, cost-utility, cost-benefit, cost-consequences, cost-minimization, and cost of illness, as well as trials on specific costs for procedures from the payer perspective were included. For this paper, which focuses on MIGS, clinical and economic analyses of EX-PRESS $^{\circledR}$ procedures have been excluded.

RCTs published only as abstracts were excluded as it was not possible to appraise quality. In addition, reviews/editorials, studies from low-income countries (where factors independent of the devices are likely to influence results, such as surgical facilities and training), and those not reporting the two primary outcomes were excluded.

\section{Study Selection}

Titles and abstracts of all electronically identified studies were reviewed independently by two reviewers. Data from studies were extracted and assessed by one reviewer. Results were reported according to the Preferred Reporting Items for Systematic Reviews and Meta-Analyses (PRISMA) guidelines for systematic reviews [24]. Selected studies were typically RCTs, although non-RCTs and gray literature were also assessed where information was lacking. For a list of sources used for gray literature searches, please see supplementary online material Table 3.

\section{Risk-of-Bias Assessment and Data Collection}

Risk-of-bias assessments provide a methodological way of analyzing whether the true effect of interventions is reported correctly, misdirected, or underreported. The risk of bias across studies was assessed using the Cochrane Collaboration Risk of Bias tool (CCRBT) and Review Manager 5.3 (RevMan) [25]. The CCRBT addresses the 
following six domains of potential bias that could compromise the integrity or credibility of a study: selection bias, performance bias, detection bias, attrition bias, reporting bias, and other bias (e.g., conflict of interest and financial disclosures declared). Assessments were made within each domain for one or more areas of potential bias towards each individual study outcome. For each domain assessment, the risk of bias was divided into two sections, the first providing support for judgement using free text by reviewers to document evidence or judgements inferred upon the paper, and the second assessing bias risk from a three-tiered approach: low risk, high risk, or unclear risk (if study information was insufficient) selected as relevant to each study [26]. To further reduce bias risk, two reviewers used the tool independently [26-28].

Clinical evidence grading was performed by two reviewers and disagreements resolved through discussion and agreement. To allow comparability of the economic evidence, costs were converted to pounds sterling $(£)$ using Organisation for Economic Co-operation and Development exchange rates [29], and inflated to 2016 values (the most recent index year) using the Hospital and Community Health Services (HCHS) pay and price inflation index [30] (where the cost year was not reported, original currencies were used).

\section{Outcomes}

Clinical outcomes reviewed were the change from baseline in mean IOP levels described as mean IOP level at longest follow-up, or as a relative reduction (from baseline) in IOP. Change in topical glaucoma medication was also reviewed, described as a reduction in number of eye drops used by patients at longest follow-up. Safety was assessed by harm and adverse events (AEs) reported as a sum of all events per MIGS device. Economic outcomes were described by cost-effectiveness and cost of treatment (MIGS, trabeculectomy, medication) sourced from various trials and HTAs.

\section{RESULTS}

\section{Study Selection}

The initial search yielded 1706 unique references which were de-duplicated to 1471 records. These were then screened by title or abstract to 148 records, which were further assessed on full text for relevance. This full analysis set included results for non-MIGS procedures with EX-PRESS (eight RCTs, four nonRCTs, and two economic publications) which have been excluded from this present analysis which focuses on MIGS. A total of nine RCTs, seven non-RCTs, and 23 economic studies were analyzed specifically for MIGS, which are presented in this paper. A flow diagram depicting the study selection for both the full set and that specific to MIGS (i.e., without EX-PRESS studies) is shown in Fig. 1.

\section{Study Characteristics}

All the nine RCTs included in this review, shown in Table 1, reported IOP-lowering interventions in patients with POAG. There were seven RCTs on iStents ${ }^{\circledR}$ [31-37] of which three reported the clinical effectiveness of one iStent implantation combined with cataract surgery compared with cataract surgery alone $[31,33,35]$, three reported the clinical effectiveness of two iStent implantation devices $[32,34,37]$, and one reported clinical effectiveness in three intervention arms using different quantities of implanted iStent devices [36]. There was a single RCT for the Hydrus ${ }^{\circledR}$ Micro-Stent [38], and one on the CyPass ${ }^{\circledR}$ Micro-Stent [39], both of which compared MIGS device combined with cataract surgery vs cataract surgery alone.

A total of seven non-RCTs (three iStent ${ }^{\circledR}$, three CyPass ${ }^{\circledR}$, and one Hydrus ${ }^{\circledR}$ ) and 23 economic trials were also assessed for MIGS. The characteristics of the non-RCTs are shown in the supplementary online material Table 2. 


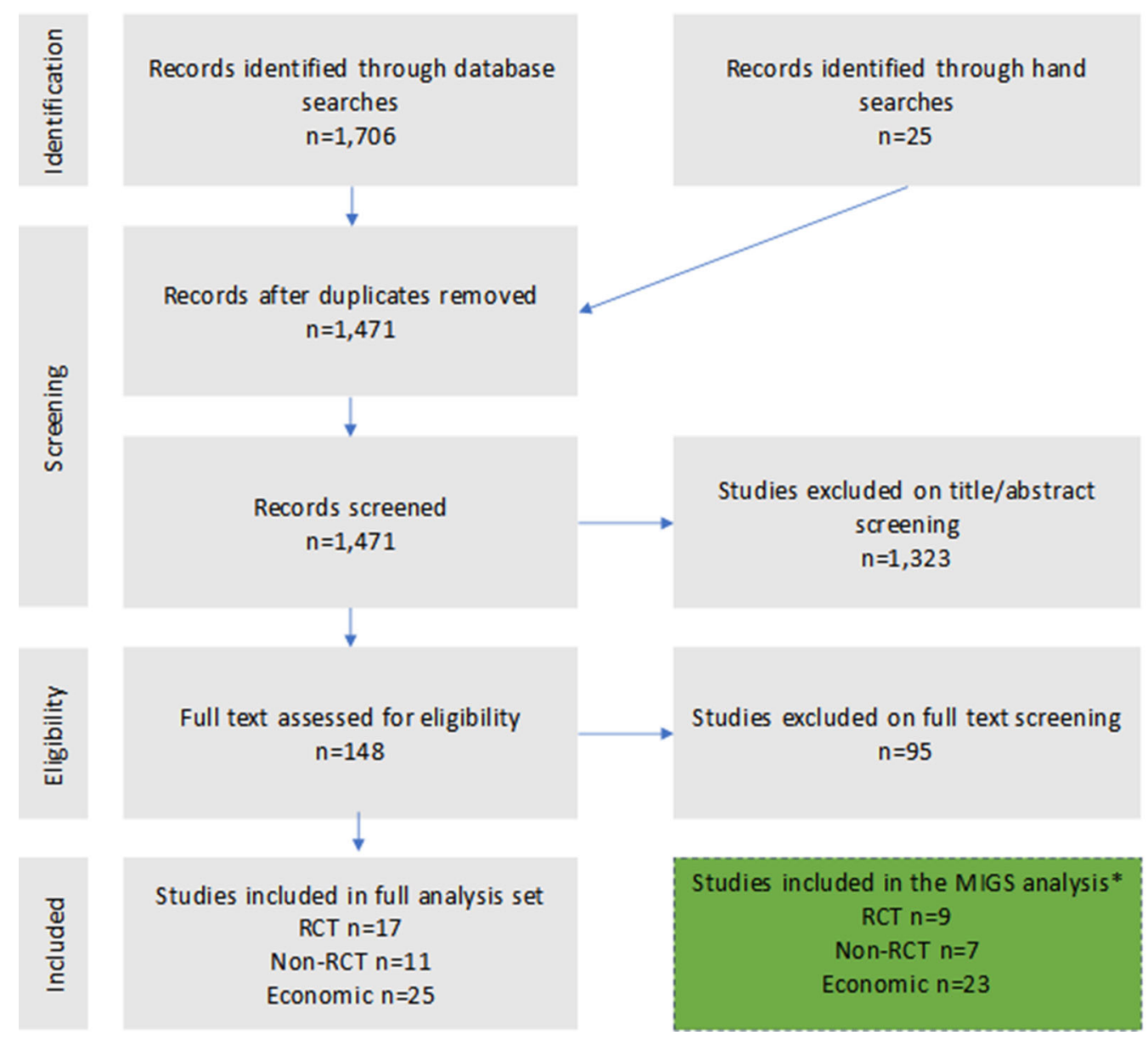

Fig. 1 Preferred Reporting Items for Systematic Reviews and Meta-Analysis (PRISMA) flow diagram for the literature screening. *Please note that this publication presents results only for MIGS devices and we have

excluded our separate analysis of device-augmented trabeculectomy using EX-PRESS ${ }^{\circledR}$. In total seven RCTs and two economic studies for EX-PRESS ${ }^{\circledR}$ have been excluded from the above final set for this present analysis

\section{Risk of Bias}

All RCTs were analyzed for potential risk of bias. Given the objective nature of IOP measurements, reviewers judged that a lack of blinding to outcome assessment would be unlikely to increase the risk of bias for IOP measurements. All outcomes for the detection bias domain were therefore judged to be of low risk as shown in supplementary online material Fig. 1. A summary of the reviewers' judgements on risk of bias for each of the nine MIGS RCTs is shown in Fig. 2. RCTs were judged to have a risk of bias for issues such as financial matters or conflicts of interest [32-34, 36, 40] and lack of evidence

of allocation concealment and blinding, or lack of evidence of sequence generation of randomization and allocation concealment [37]. In one study [34], reviewers identified three domains of bias; hence interpretation of outcomes from this study was with caution.

Overall, RCTs with the iStent and CyPass devices were judged to have the lowest risk of bias; two Hydrus Micro-Stent RCTs were judged to have six out of seven low-risk domain outcomes, although these had conflicts of interest and financial affiliation potential bias; and eight RCTs on the iStent were judged to have potentially high risk of bias to study outcomes. 


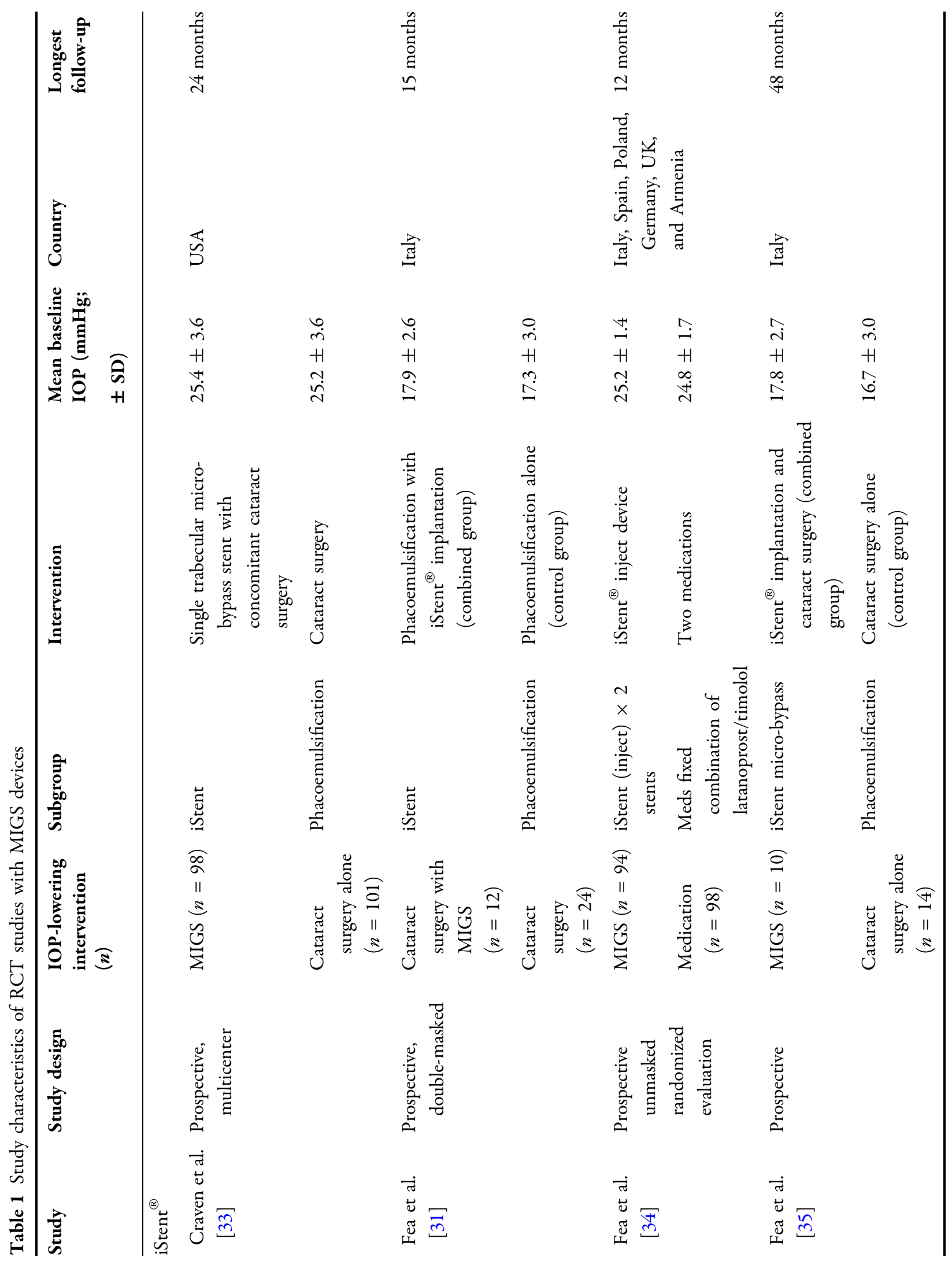




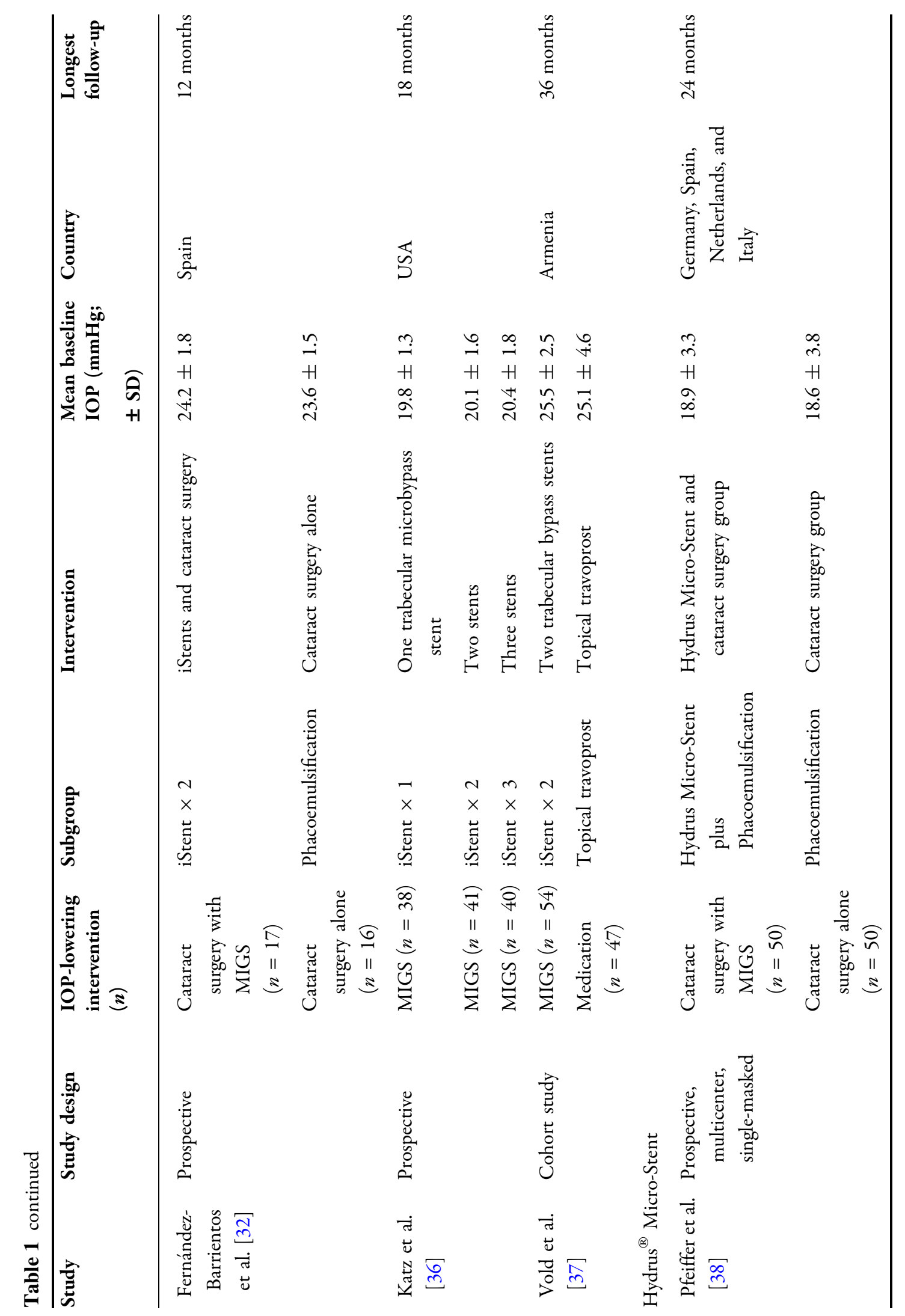




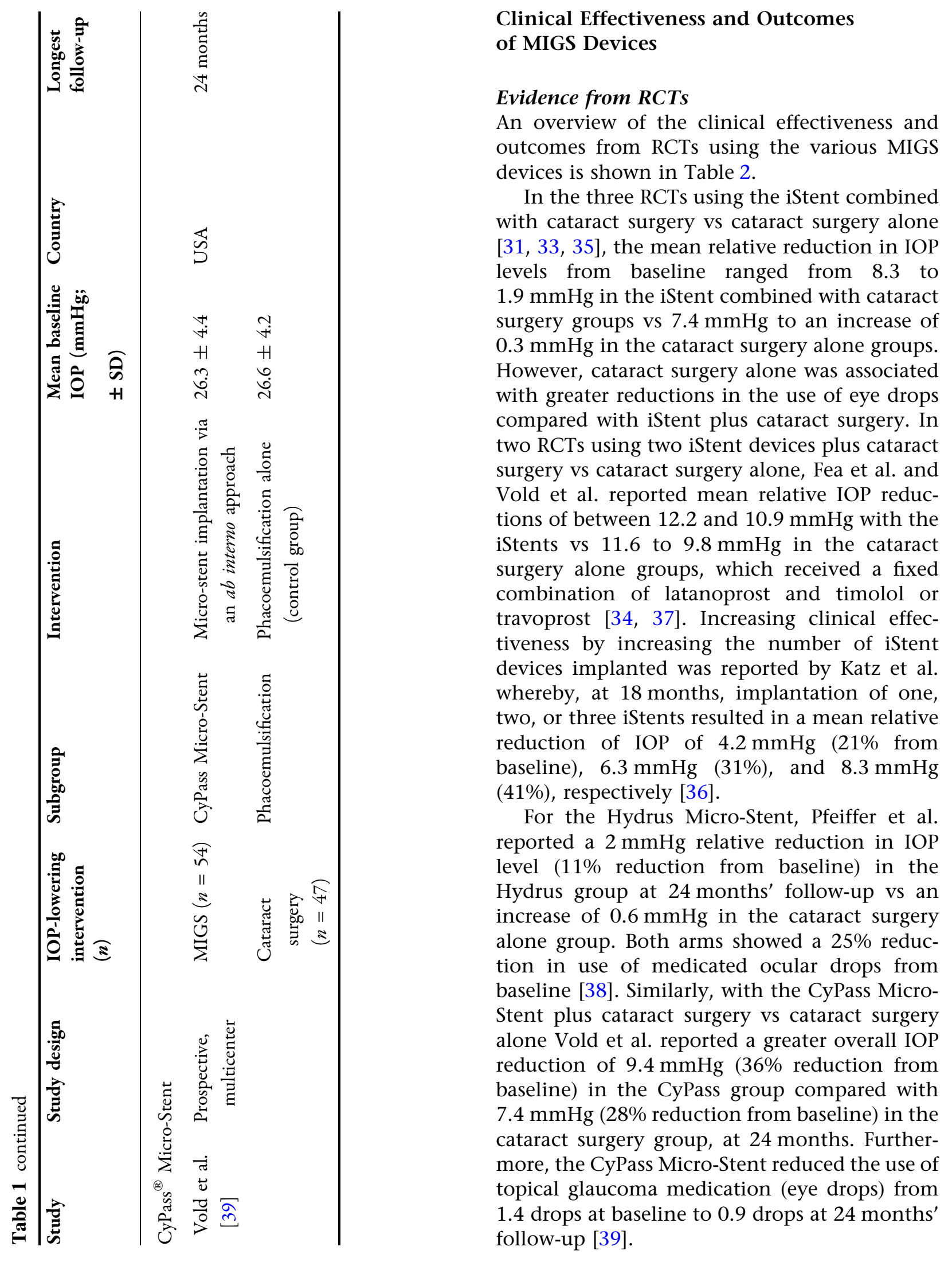

\section{Evidence from RCTs} devices is shown in Table 2.

In the three RCTs using the iStent combined surgery alone in IOP levels from baseline ranged from 8.3 to surgery groups vs $7.4 \mathrm{mmHg}$ to an increase of $0.3 \mathrm{mmHg}$ in the cataract surgery alone groups. However, cataract surgery alone was associated ith greater reductions in the use of eye drops compared with istent plus cataract surgery. In two RCTs using two iStent devices plus cataract surgery vs cataract surgery alone, Fea et al. and Vold et al. reported mean relative IOP reductions of between 12.2 and $10.9 \mathrm{mmHg}$ with the iStents vs 11.6 to $9.8 \mathrm{mmHg}$ in the cataract surgery alone groups, which received a fixed combination of latanoprost and timolol or travoprost [34, 37]. Increasing clinical effectiveness by increasing the number of iStent devices implanted was reported by Katz et al whereby, at 18 months, implantation of one, two, or three iStents resulted in a mean relative reduction of IOP of $4.2 \mathrm{mmHg}(21 \%$ from baseline), $6.3 \mathrm{mmHg}$ (31\%), and $8.3 \mathrm{mmHg}$ $41 \%)$, respectively [36].

For the Hydrus Micro-Stent, Pfeiffer et al. reported a $2 \mathrm{mmHg}$ relative reduction in IOP level (11\% reduction from baseline) in the Hydrus group at 24 months' follow-up vs an increase of $0.6 \mathrm{mmHg}$ in the cataract surgery alone group. Both arms showed a $25 \%$ reduction in use of medicated ocular drops from baseline [38]. Similarly, with the CyPass MicroStent plus cataract surgery vs cataract surgery alone Vold et al. reported a greater overall IOP reduction of $9.4 \mathrm{mmHg}$ (36\% reduction from baseline) in the CyPass group compared with $7.4 \mathrm{mmHg}$ (28\% reduction from baseline) in the cataract surgery group, at 24 months. Furthermore, the CyPass Micro-Stent reduced the use of topical glaucoma medication (eye drops) from follow-up [39]. 


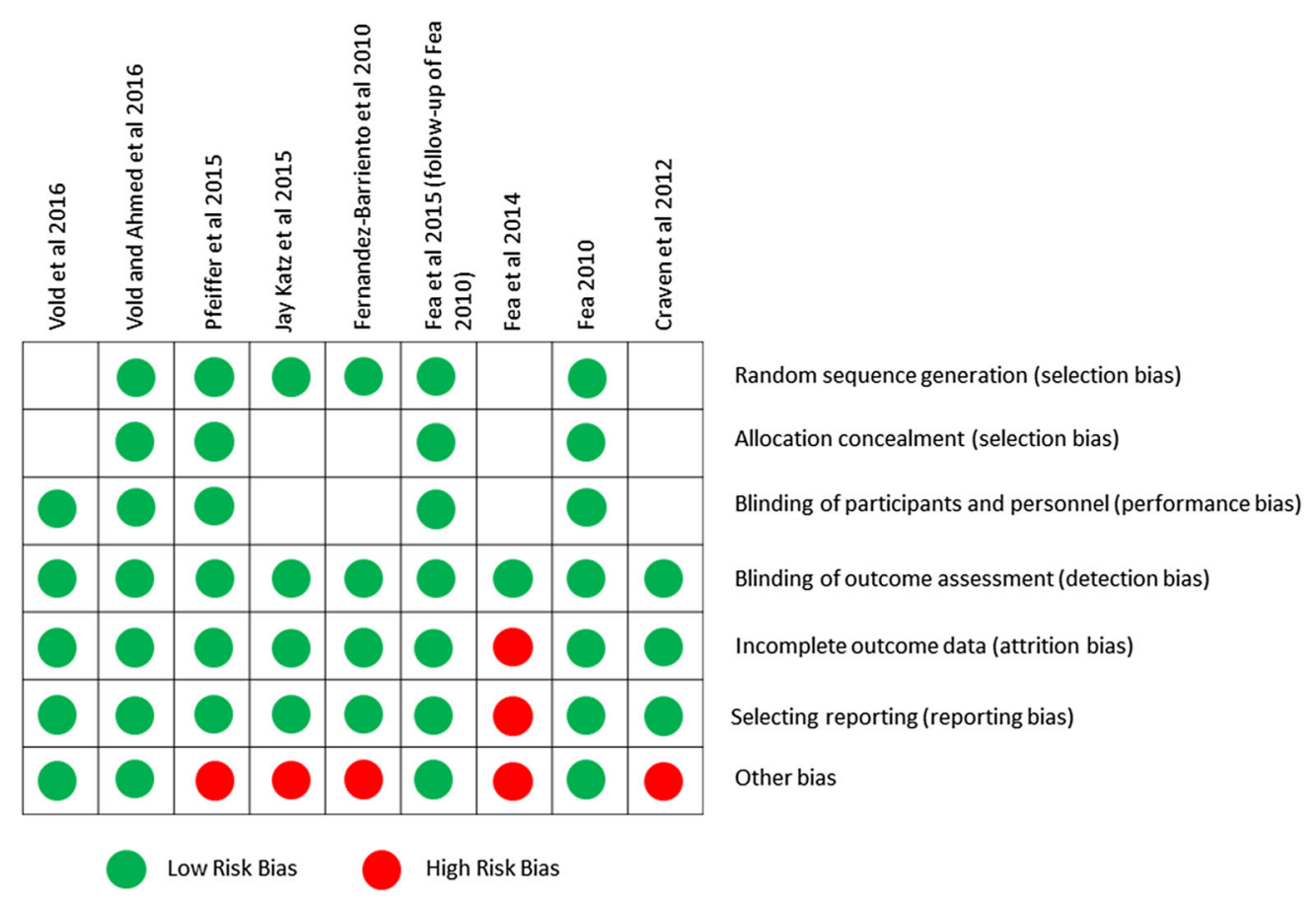

Fig. 2 Reviewers' judgement for each risk-of-bias item per RCT

\section{Evidence from Non-RCTs and Gray Literature} Non-RCTs and gray literature were used, where possible, to provide further clinical effectiveness evidence. Non-RCTs were identified for MIGS devices, and in some cases gray literature was identified and reviewed where information was lacking. For example, as no RCTs or non-RCTs were available for the XEN device, gray literature from posters and abstracts were used. Details of these sources are shown in the supplementary online material in Table 2 for nonRCTs and Table 3 for XEN-related gray literature.

Non-RCTs using the iStent included various combinations such as iStent with cataract surgery [41], iStent alone [42], and iStent plus cataract surgery compared with trabeculectomy plus cataract surgery [43]. The mean baseline IOP in these trials ranged from 17.5 to $22.3 \mathrm{mmHg}$. Kurji et al. reported the lowest follow-up IOP of $13.6 \mathrm{mmHg}$ (22\% relative reduction from baseline) [43], while the greatest decrease in mean baseline IOP of 21.3 to $14.0 \mathrm{mmHg}$ (34\% decrease) for two iStents with micro-incision cataract surgery (MICS) was reported by Gonnerman et al. at 12-month follow-up [41]. The greatest reduction in medicated hypotensive drops was reported by Khan et al. with a reduction in number of drops from 2.86 preoperative/at baseline to 1.22 at 12 months [42]. A number of case series were also identified for the iStent. In one comparative series based in Canada, the implantation of two iStents vs three iStents resulted in a similar (20\%) reduction from baseline in IOP levels after 12-month follow-up [44]. The differential in IOP reduction using two vs three iStents was less pronounced than in the RCT reported by Katz et al. in which follow-up was at 18 months [36]. Similarly, in the UK-based Manchester iStent study, a prospective uncontrolled interventional case series, Tan and Au reported a $19 \%$ reduction in IOP levels from baseline after 36 months (baseline IOP, $21.2 \mathrm{mmHg}$; mean IOP at longest follow-up, $17.1 \mathrm{mmHg}$ ) [45].

In a non-RCT case series with the CyPass a relative reduction in IOP of $26 \%$, over 6 months, was reported with mean IOP levels decreasing from a baseline of 21.2 to $15.6 \mathrm{mmHg}$ at follow-up [18]. At 24-month follow-up the reduction in IOP from baseline was $37 \%$ [46]. Furthermore, in patients who had 


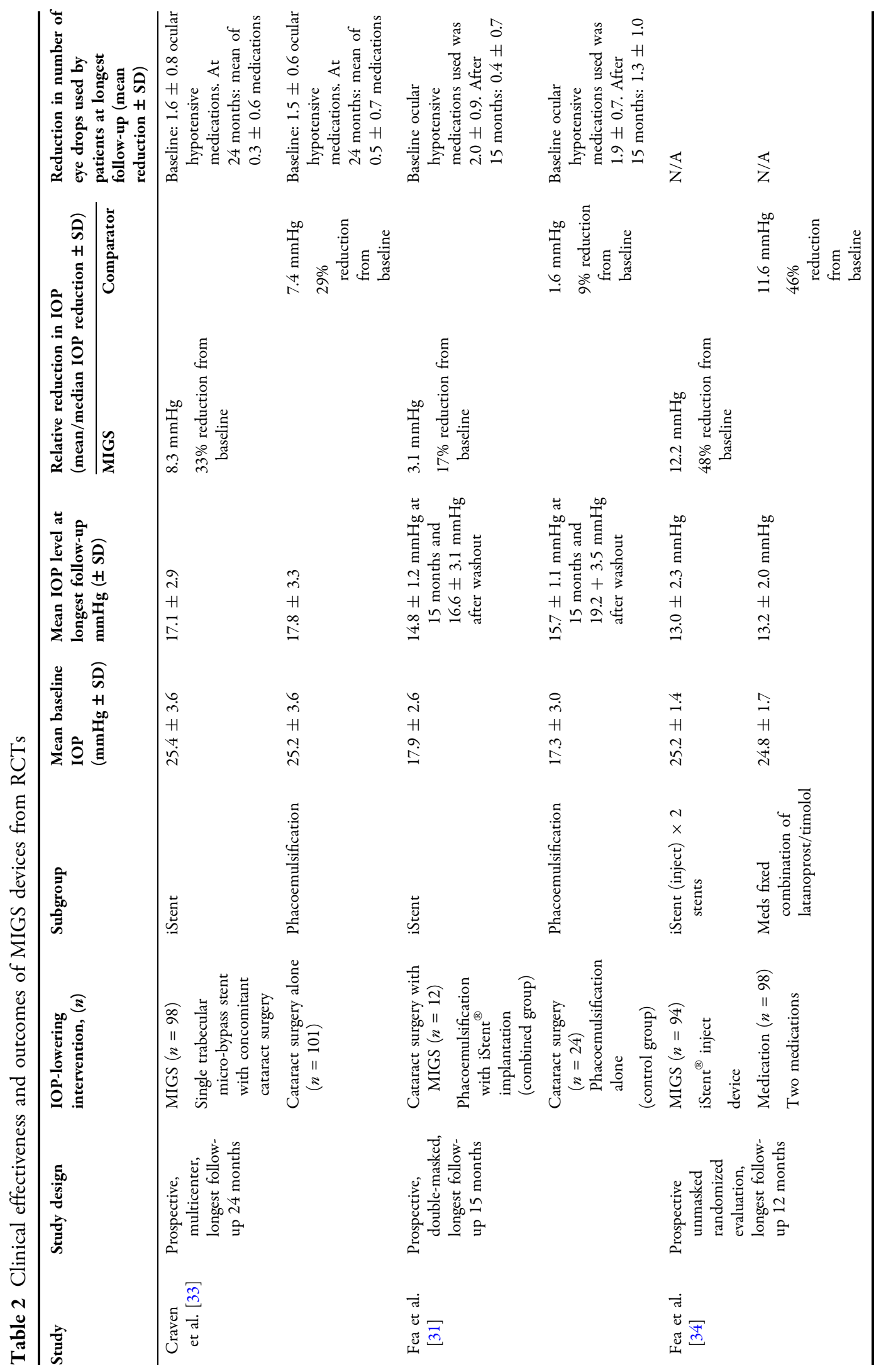




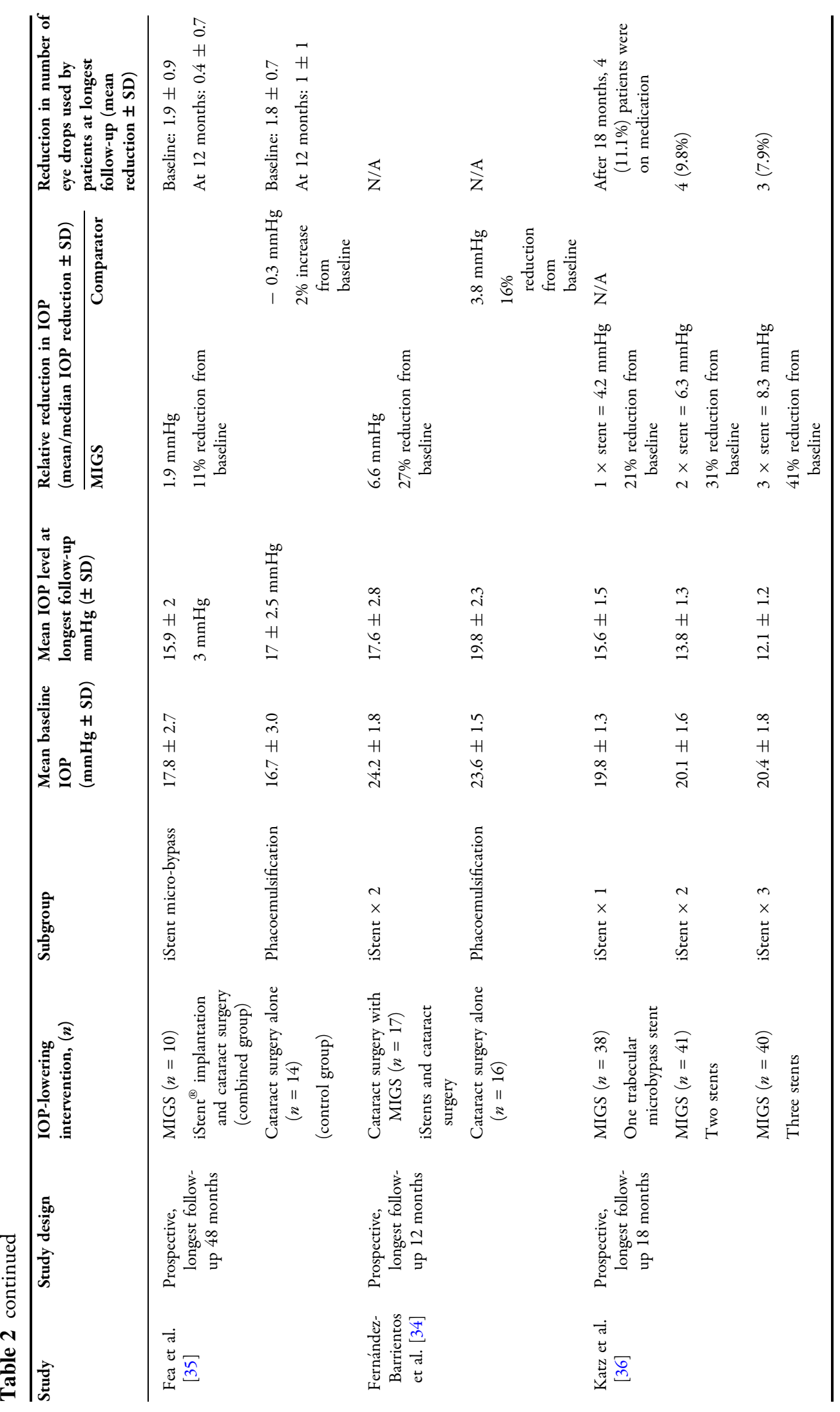




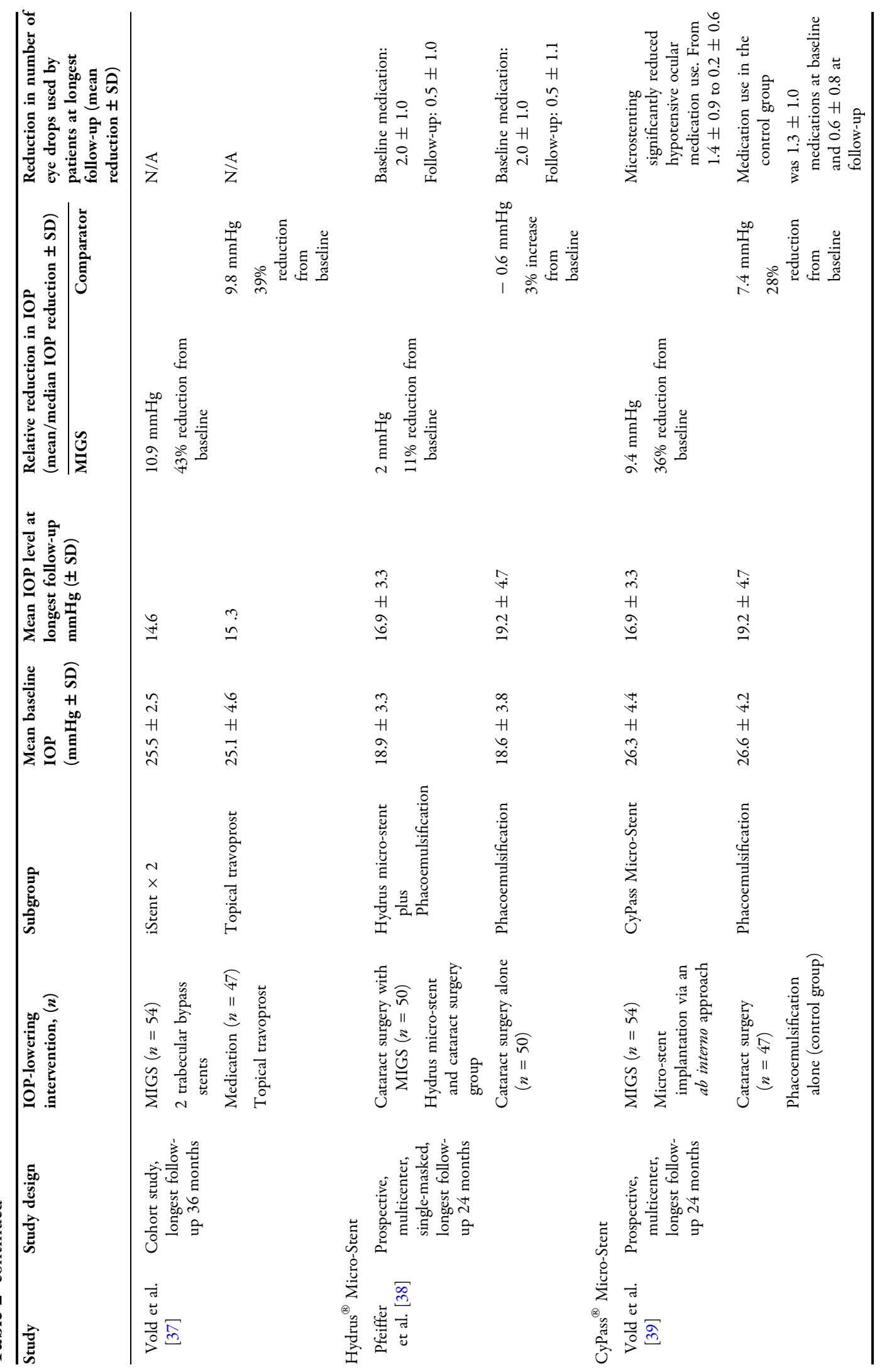


a baseline IOP below $21 \mathrm{mmHg}$ and who achieved IOP of $15.8 \mathrm{mmHg}$, there was a reduction in the use of medicated ocular drops from an average 2.0 to 1.1 [46]. Similar results were reported in another open-label interventional study across five European countries [47].

In the single identified non-RCT for the Hydrus by Fea et al., the mean IOP at baseline was similar for the Hydrus Micro-Stent vs selective laser trabeculoplasty groups at $23.1 \mathrm{vs}$ $23.2 \mathrm{mmHg}$, decreasing to 16.5 vs $15.9 \mathrm{mmHg}$ at 12-month follow-up, respectively [48].

Evidence for the XEN (XEN gel stent) device was obtained from posters and abstracts summarized in the online supplementary material Table 3 . In these abstracts, the mean preoperative (best-medicated) IOP ranged from 20.8 to $22.7 \mathrm{mmHg}$. Various reductions in IOP levels from preoperative levels have been reported for various follow-up times using the XEN device. Kersten-Gomez et al. presented an abstract in 2012 reporting an IOP decrease from 21.3 to $12.2 \mathrm{mmHg}$ at 1 week [40]. In the longest follow-up period of 4 years an IOP reduction from a baseline of 22.3 to $13.5 \mathrm{mmHg}$ (reduction of $39.5 \%$ ) was reported [49]. Although initially produced and studied with three different lumen diameters $(140,63$, and $45 \mathrm{~nm})$, the $45-\mathrm{nm}$ lumen size is the only device now recommended for implantation, as the dimensions of this device aimed to prevent postoperative hypotony [50]. Little published data exist for the XEN 45 implant. The pilot study by Sheybani et al. was on the XEN 63 and XEN 140 implants and showed a reduction in IOP from 22.4 to $15.4 \mathrm{mmHg}$ at 12 -month follow-up, with reduction in eye drops from 2.5 to 0.9 [51].

\section{Considerations and Adverse Events from MIGS RCTs}

Although MIGS devices have proven "successful", depending on the definition of success, which varies between clinicians, patients, and studies, they can be associated with various complications and AEs that require care. For example, implantation of MIGS devices may result in increased hypotony rates or bleb needling in subconjunctival placed devices.
Such procedures require additional resources in outpatient clinics and potentially additional theater time.

In this review AEs for each of the MIGS devices were extracted from the 17 RCTs, nonRCTs, and various case studies (gray literature).

The iStent, Hydrus, and CyPass devices generally have favorable safety profiles with few reported AEs. Hyphema is common with iStent and Hydrus, with rates of $19.04 \%$ for Hydrus and a few cases reported for iStent $[52,53]$. High rates of hyphema are unsurprising for these MIGS devices considering they are implanted into a highly vascular region. Other harm and AEs reported with the iStent included stent malpositioning or occlusion early in the postoperative period, affecting $4-18 \%$ of cases $[32,33,44,53]$. Corneal erosion has also been reported in one study, attributed to repeated intraoperative gonioscopy [54]: these types of risks are only relevant for MIGS that require gonioscopy.

Hypotony has also been reported for the CyPass with rates of between $2.9 \%$ and $15.4 \%$, most cases being mild and not requiring intervention $[39,46]$.

For the CyPass, in addition to hypotony, other ocular harm and AEs reported have included iritis $(8.6 \%)$, secondary ocular surgical intervention (5.5\%), corneal edema (3.5\%), and hyphema $(2.7 \%)$. However, most of these were transient and did not affect visual acuity [39]. Pfeiffer et al. reported a statistically significant $(p=0.0077)$ increase in focal peripheral anterior synechiae $(18.8 \%)$ after 2 years in patients implanted with the Hydrus combined with cataract surgery [38].

Limited information is currently available on the safety profile of XEN; the manufacturer's website states that postoperative adverse events have included hypotony (defined as IOP below $6 \mathrm{mmHg}$ at any time) in $24.6 \%$ of subjects (with no associated clinically significant consequences, no cases of persistent hypotony, and no surgical intervention required), an IOP increase of at least $10 \mathrm{mmHg}$ from baseline in $21.5 \%$ of patients, and needling procedure rates of $32.3 \%$ [55]. The high rates of bleb needling reported after XEN insertion potentially offset the economic value of the XEN because of the 
extra surgical time and patient investment required to address.

\section{Economic Outcomes with MIGS Devices}

\section{Cost-Effectiveness}

As there is limited available evidence on the cost-effectiveness of MIGS as primary interventions for glaucoma $[21,56]$, it remains unclear whether the cost of using MIGS is outweighed by cost savings through decreased medication and need for further interventions. The few available studies are either retrospective case studies or industry-sponsored RCTs with short follow-up times [57].

Medical management, stand-alone cataract surgery, and cataract surgery with iStent implantation were compared over 5 years in patients with cataract and glaucoma but inadequately controlled IOP with two medications. The study used a Markov model and a public third-party payer perspective (Ontario Health Insurance Plan). Compared with medical management, the incremental cost-effectiveness ratio (ICER) of iStent plus cataract surgery was CA $\$ 6824 / q u a l i t y$-adjusted life year compared with $\$ 4179 /$ quality-adjusted life year (cost year not stated) for cataract surgery alone. The ICER for iStent plus cataract surgery compared with cataract surgery alone was not reported [58].

Cost-effectiveness evidence for CyPass and Hydrus Micro-Stents or the XEN device was not available. A summary of the studies identified for economic evidence and reported costs is shown in Table 3.

\section{Cost of Treatment}

Of the studies reporting economic evidence for glaucoma treatment, the majority reported total, average direct costs for management strategies based on bottom-up costing or retrospective claims and registry review. Most studies included established care pathways, such as medical management, trabeculectomy, and laser surgery. Where currencies and base years were reported, current prices (GBP 2016) were calculated for costs.

As part of the Manchester iStent study, Tan et al. reported that in 36 patients who completed the 3-year follow-up the overall cost of combined cataract surgery and iStent implantation was $£ 829.32$ more in total than conservative management with branded eye drops and $£ 14,176.90$ more if generic drops were used [45]. No cost-effectiveness was reported and costs did not include follow-up care after iStent insertion or other downstream health care utilization [45].

Economic evidence suggests that iStent implantation and follow-up costs are higher than trabeculectomy costs, but the incremental cost-effectiveness of these implants remains unknown.

The majority of studies on the treatment cost of trabeculectomy and other routine procedures have reported mean direct health care costs per patient with glaucoma, rather than for specific treatments. Per patient costs include consultations, procedures (trabeculectomy, laser surgery, etc.), and medications, generally averaged across the study population. On the basis of this criterion, Olsen et al. reported the total mean annual direct glaucoma-specific health care costs per patient to be $£ 261.69$, which included both primary (visits, examinations, laser treatment) and secondary care (in- and outpatient episodes) costs [59]. This approach has also been used in other studies in which the mean annual cost per patient was below $£ 500[60,61]$. Some studies have addressed the cost of specific treatment strategies, such as medical management vs trabeculectomy [62], different medical management strategies [63], observation only vs medical therapy or laser treatment [64], or different treatment targets for IOP and visual field measurement frequencies [65]. A small number of studies have considered the impact of treatment setting on cost $[66,67]$. In a study reported by Sharma et al. community clinics were more expensive to run than hospital-based glaucoma clinics, over the course of a year, when implementation and opportunity costs but not health care or follow-up costs were considered; the authors concluded that this was due to higher overhead costs in the community setting [66]. In another study a glaucoma follow-up unit (GFU), staffed with optometrists and ophthalmic technicians, was compared with usual care provided by glaucoma 


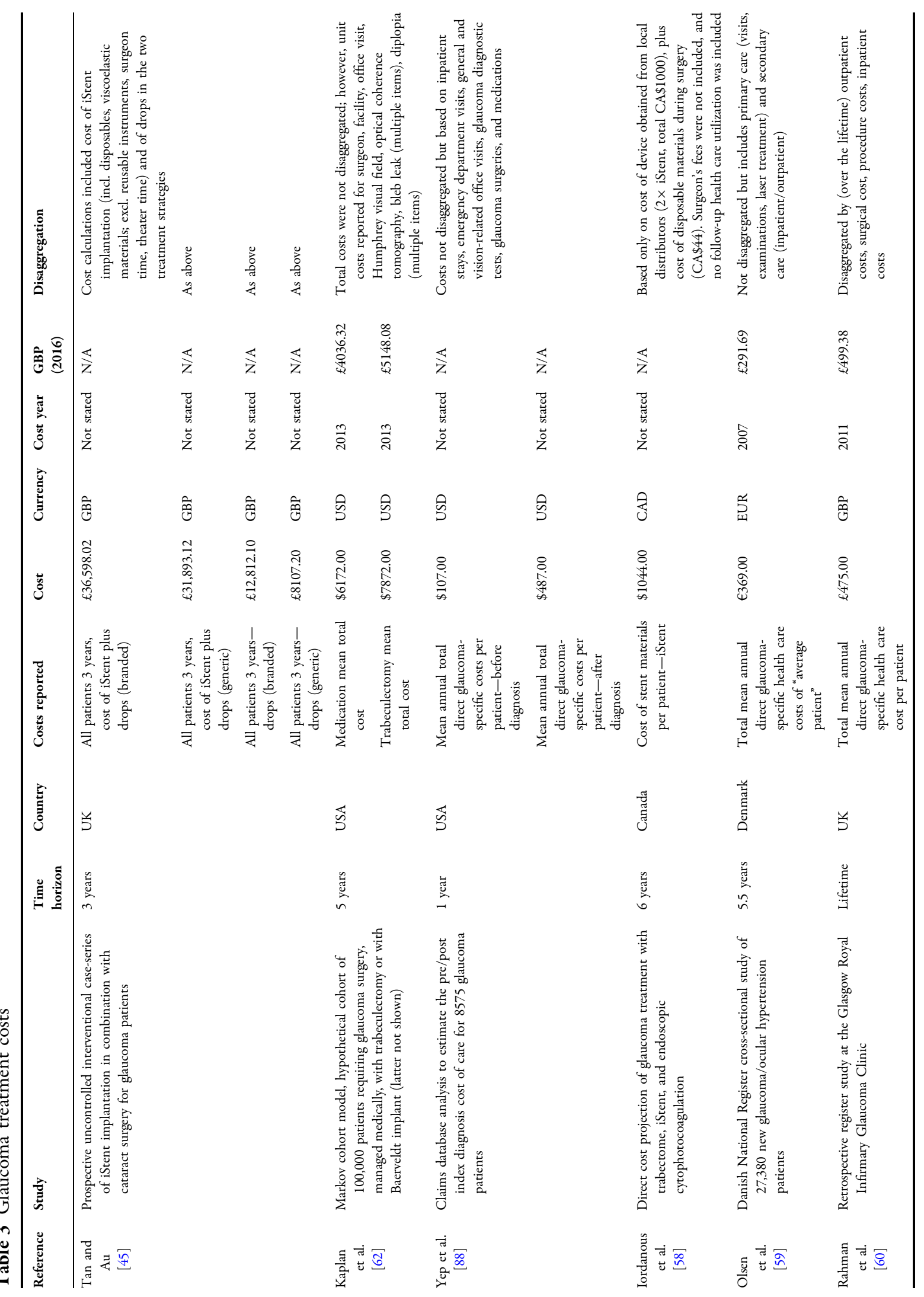




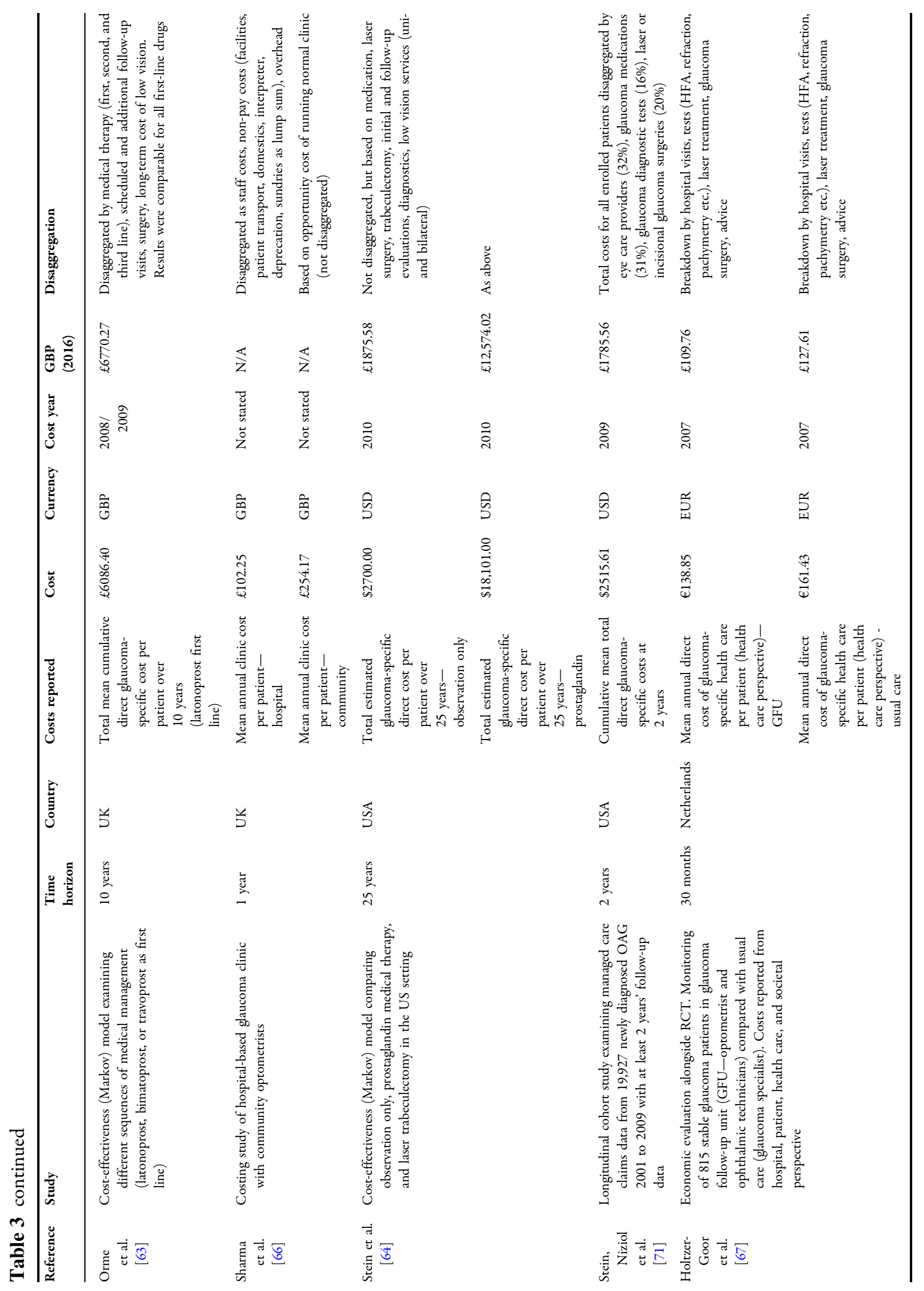




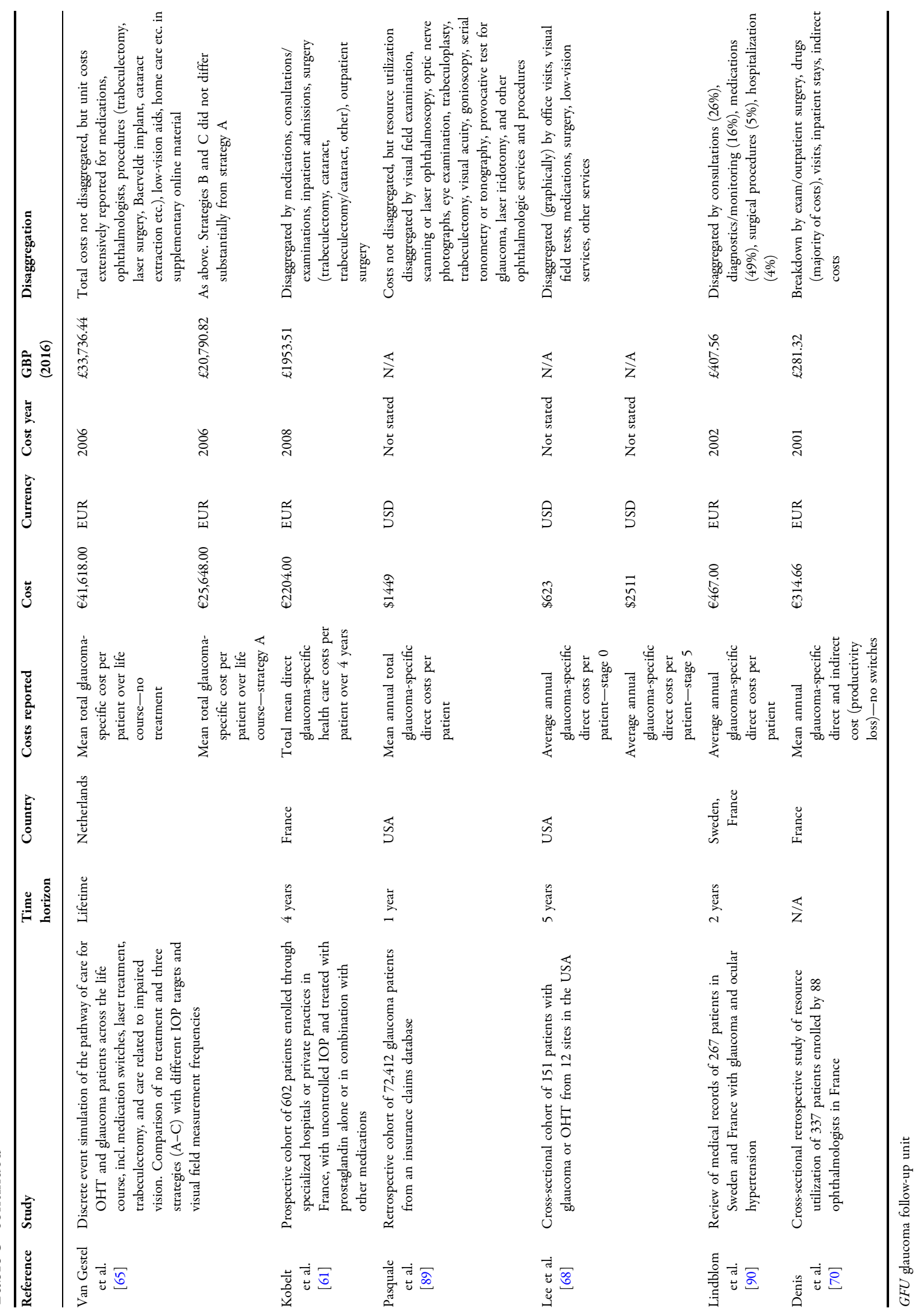


specialists. Findings from this study showed the mean direct annual cost per patient to be lower in the GFU arm (£109.76), accounting for hospital visits, tests, interventions (laser treatment, trabeculectomy, etc.), and other costs, vs usual care $(£ 127.61)$ [67].

Studies have been conducted to examine the variation in cost in patients with POAG. A number of factors have been identified that are associated with higher or lower mean costs of care. Disease stage has been identified as a predictor of higher cost [68, 69]. Long-term direct cost of 194 glaucoma patients in France, Germany, Italy, and the UK was linearly associated with disease stage, estimated at $€ 455 /$ personyear at disease stage 0 vs $€ 969 /$ person-year at disease stage 4 across the four countries [69]. Other studies have highlighted treatment changes/switches as an important predictor of costs $[59,61,70]$. For example, Danish registry data show higher costs associated with treatment changes, longer treatment duration, and age [59]. Finally, Stein et al. [71] examined factors associated with higher treatment costs and identified comorbidities as significant covariates (diabetic retinopathy, age-related macular degeneration, cataract, pseudophakia/aphakia) associated with increased cost. In the UK, the use of glaucoma medications has been analyzed on the basis of Prescription Cost Analysis data [72]. In 2009 NICE introduced clinical guidance on ocular hypertension and glaucoma, recommending prostaglandin analogues as first-line medication, and beta-blockers as first-line medication for patients with IOP levels between 26 and $32 \mathrm{mmHg}$, pachymetry $555-590 \mu \mathrm{m}$, and age below 60 years [73]. Between 2000 and 2012, prescriptions in the UK increased from 4.76 million to 7.96 million (up 67\%), with drug costs almost doubling from $£ 55.2$ million to $£ 103.7$ million. During this period, the overall use of prostaglandin increased while the use of beta-blockers decreased. There was significant heterogeneity in the drugs dispensed, with 40 medications being prescribed at a rate of more than 10,000 prescriptions per year. Latanoprost was prescribed approximately three times more frequently than the second most frequently prescribed drug; however, this cost has decreased following the availability of generic latanoprost [72].

HTA appraisals may be a potential source for economic data; however, research for this review identified records only for XEN in the NIHR-HTA database. Furthermore, the XEN HTA had no appraisal of the clinical or economic benefits of the device.

\section{DISCUSSION}

\section{Clinical and Economic Outcomes}

Primary open-angle glaucoma is a major public health problem with its increasing prevalence and substantial impact on quality of life for patients, their families, and caregivers. MIGS procedures are a heterogenous group of techniques that seek to reduce IOP with lower risk than more established filtration surgery procedures: they may increase trabecular outflow by bypassing the trabecular meshwork, increase uveoscleral outflow via suprachoroidal pathways, or create a subconjunctival drainage pathway. Although clinical experience with MIGS is increasing, and they may provide safety advantages over trabeculectomy, issues remain such as surgical difficulty, limited efficacy, complications, and the absence of long-term data.

In this review MIGS were linked to clinical disadvantages such as insufficient IOP reduction, surgical complexity, device failure, and other potential risks and AEs. For MIGS devices in which bleb management (such as needling, most commonly, and treatment of leakage) is frequent practice (i.e., Xen), many studies do not classify these as an $\mathrm{AE}$ and thus the true impact of bleb management remains unclear. These types of AEs require postoperative interventions which can have an impact on time and outpatient resources/costs. While various forms of trabeculectomy can achieve postoperative IOP of $11.0-13.0 \mathrm{mmHg}[15,74,75]$, MIGS devices described in this review were typically associated with higher postoperative IOP levels. This therefore suggests that MIGS devices are best suited for patients with mild to moderate disease in which lower target IOPs are not 
necessary, or as a method by which patients can reduce their topical hypotensive load. For example, mean IOP at the longest follow-up (36 months) reported for the iStent as a separate glaucoma intervention was $14.6 \mathrm{mmHg}$ [37], while the iStent combined with cataract surgery resulted in IOP levels of $15.9 \mathrm{mmHg}$ at 48 months [35], $17.1 \mathrm{mmHg}$ at 24 months [33], and $14.8 \mathrm{mmHg}$ at 15 months [31]. The lowest IOP of $13.0 \mathrm{mmHg}$ was reported with the shortest follow-up of 12 months using the iStent. This was achieved by implanting two stents; however, this was on a slight up-trend from month 6 (12.7 mmHg) onwards [34]. Although the iStent is associated with fewer risks and AEs compared to other MIGS devices, it has limited effectiveness in IOP lowering, which is dictated by the episcleral venous pressure. In addition, iStent implantations, which require tilting microscopes, in-theater gonioscopy, and lens extraction, tend to be restricted to elderly patients with cataracts, and it is not possible to ascertain blockage of an iStent as there is no bleb.

Clinical effectiveness of the Hydrus MicroStent appeared to be similar to the iStent with a mean IOP level of $16.9 \mathrm{mmHg}$ at 24-month follow-up [38]. However, it is unknown whether surgically implantation of the Hydrus may be more challenging than the iStent, or if complications vary: there are a lack of published data. The CyPass RCT showed a reduction in IOP by $36 \%$ at 24 months, plus reduction in topical glaucoma medications [39]. Similar findings are also seen in real-world observational studies [47]. The suprachoroidal space is highly vascular, which in theory potentially increases the risk of an intraoperative suprachoroidal hemorrhage with suprachoroidal devices; however, there is currently no evidence to substantiate this fear.

Details of clinical evidence of the XEN device are currently unavailable and evidence from abstracts is limited on safety data. From available information, IOP reduction with the XEN device may be comparable to other MIGS devices with the lowest reported follow-up IOP of $13.0 \mathrm{mmHg}$ at 12 months [76] and the highest of $15.9 \mathrm{mmHg}$ at 12 months [77]. These preliminary reports are based on non-peer- reviewed materials and are subject to significant uncertainty. A potential concern with the XEN device is that it is porcine gelatin-based; implantation of porcine-derived material may be an issue in patients with certain religious and personal beliefs [78].

Economic outcomes were challenging to assess in this review because of limited availability of information on cost-effectiveness and cost of treatment of all MIGS devices. Although there was one economic study with the iStent [58], there was no cost-effectiveness evidence. As disease stage has been identified as a predictor of higher management costs, devices aimed at advanced glaucoma patients or those with high IOP may have higher cost-savings potential $[68,69]$.

\section{MIGS Devices and Unmet Need}

The comparative effectiveness of a MIGS device is dependent on implantation site, device material, and design. A key challenge is in using materials that induce minimal tissue reaction and scarring. Despite antimetabolite use, the subconjunctival space is prone to fibrosis, hence a reduction in efficacy or late failure. This is certainly the case in glaucoma patients using long-term preserved drop therapy, as the conjunctiva has been shown to be pro-inflammatory and primed for scarring in the case of further insult [79]. Using the suprachoroidal route (i.e., CyPass and iStent Supra) avoids subconjunctival filtration bleb-related complications including hypotony, leakage, bleb failure, bleb-related infection (short- and longterm), and discomfort with foreign body sensation or pain [80]. The suprachoroidal space also offers the opportunity for significant reductions in IOP. Evidence suggests that a negative pressure gradient exists between the anterior chamber and the suprachoroidal space, promoting aqueous outflow through a vacuum-like effect [81]. However, it is more invasive and intraocular than $a b$ externo procedures, and although suprachoroidal hemorrhage [82] has not been reported, lack of long-term data makes it difficult to confirm clinical benefits and safety. Furthermore, implants placed in the 
suprachoroidal space do not escape tissue reaction and implant failure through fibrosis [83].

Larger, multicenter, randomized trials and real-world observations are needed for all MIGS devices to better assess their clinical and economic effectiveness. In addition, this review highlights the unmet need for better treatment options for patients with open-angle glaucoma; MIGS devices should be simple for surgeons to use and provide sustained long-term IOP-reducing effect, with postoperative management suitable to the general ophthalmologist and few potential complications (e.g., ideally with minimal hypotony and easy-to-manage blebs). In addition, rapid visual recovery would be ideal. Such qualities would be better for patients as well as for busy outpatient settings where the management of complications can place a burden on economic resources. The use of MIGS devices may also benefit from defined treatment options for specific patient groups (such as those with high IOP), and guidelines for surgeons as to which device should be used in which patient population.

Since completion of this systematic review study in December 2016, a number of commentaries and reviews have been published discussing the efficacy and safety of MIGS devices [84-87]. Our findings agree with other reports in that current data indicate a balance between potential IOP lowering and AEs while acknowledging the lack of comparable longterm data [84-87]. A common theme, expanded upon in this systematic review, is the importance of understanding the characteristics of each MIGS device (e.g., mode of action and safety profile, as well as the IOP-lowering potential) and how these relate to the specific target population profile [85, 87]. However, none have reviewed or discussed in detail the economic data, which further highlights the need for additional information on which to distinguish between the various MIGS devices available.

\section{Study Strengths and Limitations}

A major strength of this research is the comprehensive, structured, and systematic approach in searching the literature to identify all studies that report clinical and or economic outcomes in the glaucoma surgery segment. To the best of our knowledge this is the first systematic review to include economic outcomes in currently available MIGS devices. Possible limitations may be the difficulty in making direct comparisons either between studies or MIGS devices as well as the limited availability of suitable economic data on MIGS devices. A further limitation is that the search and analysis are based on published literature up to December 2016. Systematic reviews are universally limited in scope by providing a snapshot of evidence in time based on tight inclusion and exclusion criteria, and cutoff dates for literature inclusion: a trade-off for the methodological robustness. As real-world experience grows with MIGS we suggest conducting "living" systematic reviews that are continually updated, incorporating new relevant RCT and non-RCT evidence as it becomes available to best inform evidencebased practice.

\section{CONCLUSION}

Despite the increasing prevalence of POAG as a leading cause of blindness, and the availability of treatments such as hypotensive medicated ocular drops, trabeculectomy, or, more recently, MIGS devices, there still remains a need for treatments that are easy to implement and reduce IOP levels without increasing postoperative aftercare and cost.

\section{ACKNOWLEDGEMENTS}

Funding. This systematic review and article processing charges were funded by Santen $\mathrm{GmbH}$, Germany. All authors had full access to all of the data in this study and take complete responsibility for the integrity of the data and accuracy of the data analysis.

Editorial Assistance. Writing and editorial support has been provided by Valid Insight. This support was funded by Santen $\mathrm{GmbH}$, Germany. We also acknowledge Nik Prowse of Valid Insight for editorial assistance. 
Authorship. All named authors meet the International Committee of Medical Journal Editors (ICMJE) criteria for authorship for this article, take responsibility for the integrity of the work as a whole, and have given their approval for this version to be published.

Authors' contributions. SB was involved in designing and conducting the systematic literature review (SLR), developing the concept, and drafting and reviewing the manuscript. PA provided advice on scope of the SLR, publication concept development, drafting, reviewing, and editing the manuscript. Both authors have read and approved the final manuscript.

Disclosures. Valid Insight, the company of which Steven E Bradshaw is a director, received funding for this systematic review and its publication from Santen $\mathrm{GmbH}$, Germany. Pavi Agrawal has nothing to disclose.

Compliance with Ethics Guidelines. This article is based on previously conducted studies and does not contain studies with human participants or animals performed by any of the authors.

Data availability. All data generated or analyzed during this study are included in this published article/as supplementary information files.

Open Access. This article is distributed under the terms of the Creative Commons Attribution-NonCommercial 4.0 International License (http://creativecommons.org/licenses/ by-nc/4.0/), which permits any noncommercial use, distribution, and reproduction in any medium, provided you give appropriate credit to the original author(s) and the source, provide a link to the Creative Commons license, and indicate if changes were made.

\section{REFERENCES}

1. Tham YC, Li X, Wong TY, Quigley HA, Aung T, Cheng CY. Global prevalence of glaucoma and projections of glaucoma burden through 2040: a systematic review and meta-analysis. Ophthalmology. 2014;121:2081-90.

2. Kapetanakis VV, Chan MP, Foster PJ, Cook DG, Owen CG, Rudnicka AR. Global variations and time trends in the prevalence of primary open angle glaucoma (POAG): a systematic review and metaanalysis. Br J Ophthalmol. 2016;100(1):86-93.

3. Schmid Biggerstaff K. Primary open-angle glaucoma (POAG). http://emedicine.medscape.com/article/ 1206147-overview. Accessed 4 Aug 2017.

4. EGS. European Glaucoma Society guidelines, 4th ed. EGS; 2014. http://www.eugs.org. Accessed Aug 2017.

5. Ren R, Jonas JB, Tian G, et al. Cerebrospinal fluid pressure in glaucoma. Ophthalmology. 2010;117:259-66.

6. Wang N, Xie X, Yang D, et al. Orbital cerebrospinal fluid space in glaucoma: the Beijing intracranial and intraocular pressure (iCOP) study. Ophthalmology. 2012;119(2065-2073):e2061.

7. Weinreb RN, Aung T, Medeiros FA. The pathophysiology and treatment of glaucoma. JAMA. 2014;311(18):1901-11.

8. Kass MA, Heuer DK, Higginbotham EJ, Johnson CA, Keltner JL, Miller JP, et al. The ocular hypertension treatment study: a randomized trial determines that topical ocular hypotensive medication delays or prevents the onset of primary open-angle glaucoma (Chicago, IL: 1960). Arch Ophthalmol. 2002;120:701-13 (discussion 829-830).

9. Stolz J, Lemij H, Hoevenaars J, van der Windt C, Baudouom C. Patient satisfaction with glaucoma therapy: reality or myth? Clin Ophthalmol. 2015;9:785-93.

10. Gedde SJ, Herndon LW, Brandt JD, et al. Postoperative complications in the tube versus trabeculectomy (TVT) study during five years of follow-up. Am J Ophthalmol. 2012;153(804-814):e801.

11. Molteno AC. New implant for drainage in glaucoma. Clinical trial. Br J Ophthalmol. 1969;53:606-15.

12. Lloyd MA, Baerveldt G, Heuer DK, Minckler DS, Martone JF. Initial clinical experience with the Baerveldt implant in complicated glaucomas. Ophthalmology. 1994;101:640-50.

13. Coleman AL, Hill R, Wilson MR, et al. Initial clinical experience with the Ahmed glaucoma valve implant. Am J Ophthalmol. 1995;120:23-31.

14. Patel S, Pasquale LR. Glaucoma drainage devices: a review of the past, present, and future. Semin Ophthalmol. 2010;25:265-70. 
15. Gedde SJ, Schiffman JC, Feuer WJ, et al. Treatment outcomes in the tube versus trabeculectomy (TVT) study after five years of follow-up. Am J Ophthalmol. 2012;153(789-803):e782.

16. Spiegel D, García-Feijoó J, García-Sánchez J, Lamielle H. Coexistent primary open-angle glaucoma and cataract: preliminary analysis of treatment by cataract surgery and the iStent trabecular micro-bypass stent. Adv Ther. 2008;25:453-64.

17. Shareef S, Fea A, Ahmed IIK. The Hydrus microstent. In: Samples JR, Ahmed IIK, editors. Surgical innovations in glaucoma. New York: Springer; 2014. p. 171-4.

18. Höh H, Ahmed IIK, Grisanti S, et al. Early postoperative safety and surgical outcomes after implantation of a suprachoroidal micro-stent for the treatment of open-angle glaucoma concomitant with cataract surgery. J Cataract Refract Surg. 2013;39:431-7.

19. Lewis RA. Ab interno approach to the subconjunctival space using a collagen glaucoma stent. J Cataract Refract Surg. 2014;40:1301-6.

20. Gazzard G. Minimally invasive glacuoma surgery: MIGS. Focus. London: Royal College of Ophthalmologists; 2016.

21. Richter GM, Coleman AL. Minimally invasive glaucoma surgery: current status and future prospects. Clin Ophthalmol. 2016;10:189-206.

22. Varma R, Lee PP, Goldberg I, Kotak S. An assessment of the health and economic burdens of glaucoma. Am J Ophthalmol. 2011;152:515-22.

23. NICE. The guidelines manual. https://www.nice. org.uk/process/pmg6/chapter/introduction. Accessed Aug 2017.

24. Moher D, Liberati A, Tetzlaff J, Altman DG, Altman D. Preferred reporting items for systematic reviews and meta-analyses: the PRISMA statement. PLoS Med. 2009;6:e1000097.

25. Cochrane Collaboration. RevMan 5. http:// community.cochrane.org/tools/review-productiontools/revman-5. Accessed Aug 2017.

26. Higgins JP, Altman DG. Assessing risk of bias in included studies. In: Higgins JP, Green S, editors. Cochrane handbook for systematic reviews of interventions. Chichester: Wiley; 2008. p. 187-241.

27. Jadad AR, Enkin MW. Bias in randomized controlled trials. In: Jadad AR, Enkin MW, editors. Randomized controlled trials. Oxford: Blackwell; 2007. p. 29-47.
28. CRD. Systematic reviews: CRD's guidance for undertaking reviews in health care. York: Centre for Reviews and Dissemination, University of York; 2009.

29. OECD. Exchange rates. Paris: Organisation for Economic Co-operation and Development; 2017.

30. PSSRU. PSSRU | Unit costs of health and social care 2016. Canterbury: Personal Social Services Research Unit, University of Kent; 2016.

31. Fea AM. Phacoemulsification versus phacoemulsification with micro-bypass stent implantation in primary open-angle glaucoma. Randomized double-masked clinical trial. J Cataract Refract Surg. 2010;36:407-12.

32. Fernández-Barrientos Y, García-Feijoo J, Martínezde-la-Casa JM, Pablo LE, Fernandez-Perez C, Sanchez JG. Fluorophotometric study of the effect of the Glaukos trabecular microbypass stent on aqueous humor dynamics. Invest Ophthalmol Vis Sci. 2010;51:3327-32.

33. Craven ER, Katz LJ, Wells JM, Giamporcaro JE. Cataract surgery with trabecular micro-bypass stent implantation in patients with mild-to-moderate open-angle glaucoma and cataract: two-year followup. J Cataract Refract Surg. 2012;38:1339-45.

34. Fea AM, Belda JI, Rekas M, et al. Prospective unmasked randomized evaluation of the iStent inject $^{\circledR}$ versus two ocular hypotensive agents in patients with primary open-angle glaucoma. Clin Ophthalmol. 2014;8:875-82.

35. Fea AM, Consolandi G, Zola M, et al. Micro-bypass implantation for primary open-angle glaucoma combined with phacoemulsification: 4-year followup. J Ophthalmol. 2015; 4. Article ID 795357. https://doi.org/10.1155/2015/795357.

36. Katz JL, Erb C, Guillamet AC, et al. Prospective, randomized study of one, two, or three trabecular bypass stents in open-angle glaucoma subjects on topical hypotensive medication. Clin Ophthalmol. 2015;9:2313-20.

37. Vold SD, Voskanyan L, Tetz M, et al. Newly diagnosed primary open-angle glaucoma randomized to 2 trabecular bypass stents or prostaglandin: outcomes through 36 months. Ophthalmol Ther. 2016;5:161-72.

38. Pfeiffer N, Garcia-Feijoo J, Martinez-De-La-Casa JM, et al. A randomized trial of a Schlemm's canal microstent with phacoemulsification for reducing intraocular pressure in open-angle glaucoma. Ophthalmology. 2015;122:1283-93. 
39. Vold S, Ahmed IIK, Craven ER, et al. Two-year COMPASS trial results: supraciliary microstenting with phacoemulsification in patients with openangle glaucoma and cataracts. Ophthalmology. 2016;123:2103-12.

40. Kersten-Gomez I, Dick H. First results of the innovative minimal-invasive glaucoma surgery technique: the AqueSys Aquecentesis procedure. Eur Soc Cataract Refractive Surgeons At: Glaucoma II; 2012.

41. Gonnermann J, Bertelmann E, Pahlitzsch M, Torun $\mathrm{N}$, Klamann MKJ. Contralateral eye comparison study in MICS \& MIGS: Trabectome ${ }^{\circledR}$ vs iStent inject $^{\circledR}$. Graefe's Arch Clin Exp Ophthalmol. 2016;255(2):359-65.

42. Khan M, Saheb H, Neelakantan A, et al. Efficacy and safety of combined cataract surgery with 2 trabecular microbypass stents versus ab interno trabeculotomy. J Cataract Refract Surg. 2015;41:1716-24.

43. Kurji K, Rudnisky CJ, Rayat JS, et al. Phaco-trabectome versus phaco-iStent in patients with openangle glaucoma. Can J Ophthalmol. 2015;52(1):99-106.

44. Belovay GW, Naqi A, Chan BJ, Rateb M, Ahmed IIK. Using multiple trabecular micro-bypass stents in cataract patients to treat open-angle glaucoma. J Cataract Refract Surg. 2012;38:1911-7.

45. Tan SZ, Au L. Manchester iStent study: 3-year results and cost analysis. Eye (Lond). 2016. https:// doi.org/10.1038/eye.2016.139.

46. Höh H, Grisanti S, Grisanti S, Rau M, Ianchulev S. Two-year clinical experience with the CyPass micro-stent: safety and surgical outcomes of a novel supraciliary micro-stent. Klin Monbl Augenheilkd. 2014;231:377-81.

47. Höh H, Vold SD, Ahmed IK, et al. Initial clinical experience with the CyPass micro-stent. J Glaucoma. 2016;25:106-12.

48. Fea AM, Ahmed IIK, Lavia C, et al. Hydrus microstent compared to selective laser trabeculoplasty in primary open angle glaucoma: one year results. Clin Exp Ophthalmol. 2016;45(2):120-7.

49. Lenzhofer M, Kersten-Gomez IS, Sheybani A, et al. Four-year follow-up results after transscleral glaucoma gel stent implantation in a prospective multicentre trial. ASCRS-ASOA Symposium and Congress; 2016.

50. Sheybani A, Reitsamer H, Ahmed II. Fluid dynamics of a novel micro-fistula implant for the surgical treatment of glaucoma. Invest Ophthalmol Vis Sci. 2015;56(8):4789-95.
51. Sheybani A, Lenzhofer M, Hohensinn M, Reitsamer $\mathrm{H}$, Ahmed IIK. Phacoemulsification combined with a new ab interno gel stent to treat open-angle glaucoma: pilot study. J Cataract Refract Surg. 2015;41:1905-9.

52. Gandolfi SA, Ungaro N, Ghirardini S, Tardini MG, Mora P. Comparison of surgical outcomes between canaloplasty and Schlemm's canal scaffold at 24 months' follow-up. J Ophthalmol. 2016; 5. Article ID 3410469. https://doi.org/10.1155/2016/ 3410469 .

53. Le K, Saheb H. iStent trabecular micro-bypass stent for open-angle glaucoma. Clin Ophthalmol. 2014;8:1937-45.

54. Vandewalle E, Zeyen T, Stalmans I. The iStent trabecular micro-bypass stent: a case series. Bull Soc Belge Ophtalmol. 2009;311:23-9.

55. $\mathrm{XEN}^{\circledR}$ gel stent. https://hcp.xengelstent.com/. Accessed Aug 2017.

56. Kerr NM, Wang J, Barton K. Minimally invasive glaucoma surgery as primary stand-alone surgery for glaucoma. Clin Exp Ophthalmol. 2016;45(4):393-400.

57. Page RD, Johnson SJ. Minimally invasive glaucoma surgeries. In: Topics in cateract surgery. Avid Science; 2016. p.2-45.

58. Iordanous Y, Kent JS, Hutnik CM, Malvankar-Mehta MS. Projected cost comparison of trabectome, iStent, and endoscopic cyclophotocoagulation versus glaucoma medication in the Ontario Health Insurance Plan. J Glaucoma. 2013;23:112-8.

59. Olsen J, Berdeaux G, Skov J. Glaucoma costs in Denmark in treatment naive patients. Acta Ophthalmol. 2013;91:25-31.

60. Rahman MQ, Beard SM, Discombe R, Sharma R, Montgomery DMI. Direct healthcare costs of glaucoma treatment. Br J Ophthalmol. 2013;97:720-4.

61. Kobelt G, Texier-Richard B, Buchholz P, et al. Treatment of glaucoma in clinical practice. J Glaucoma. 2010;19:199-206.

62. Kaplan RI, De Moraes CG, Cioffi GA, Al-Aswad LA, Blumberg DM. Comparative cost-effectiveness of the Baerveldt implant, trabeculectomy with mitomycin, and medical treatment. JAMA Ophthalmol. 2015;133:560-7.

63. Orme M, Collins S, Loftus J. Long-term medical management of primary open-angle glaucoma and ocular hypertension in the UK. J Glaucoma. 2012;21:433-49. 
64. Stein J, Kim D, Peck W, Gianetti S, Hutton D. Costeffectiveness of medications compared with laser trabeculoplasty in patients with newly diagnosed open-angle glaucoma. Arch Ophthalmol. 2012;130:497.

65. Van Gestel A, Severens JL, Webers CAB, Beckers HJM, Jansonius NM, Schouten JSAG. Modeling complex treatment strategies: construction and validation of a discrete event simulation model for glaucoma. Value Health. 2010;13:359-67.

66. Sharma A, Jofre-Bonet M, Panca M, Lawrenson JG, Murdoch I. An economic comparison of hospitalbased and community-based glaucoma clinics. Eye. 2012;26:967-71.

67. Holtzer-Goor KM, van Sprundel E, Lemij HG, Plochg T, Klazinga NS, Koopmanschap MA. Costeffectiveness of monitoring glaucoma patients in shared care: an economic evaluation alongside a randomized controlled trial. BMC Health Serv Res. 2010;10:312.

68. Lee P, Walt J, Doyle J, et al. A multicenter, retrospective pilot study of resource use and costs associated with severity of disease in glaucoma. Arch Ophthalmol. 2006;124:12-9.

69. Traverso CE, Walt JG, Kelly SP, et al. Direct costs of glaucoma and severity of the disease: a multinational long term study of resource utilisation in Europe. Br J Ophthalmol. 2005;89:1245-9.

70. Denis P, Lafuma A, Berdeaux G. Medical predictive factors of glaucoma treatment costs. J Glaucoma. 2004;13:283-90.

71. Stein JD, Niziol LM, Musch DC, et al. Longitudinal trends in resource use in an incident cohort of open-angle glaucoma patients: resource use in open-angle glaucoma. Am J Ophthalmol. 2012;154(452-459):e452.

72. Connor AJ, Fraser SG. Glaucoma prescribing trends in England 2000 to 2012. Eye. 2014;28:863-9.

73. NICE. CG85: Glaucoma diagnosis and management. London: National Institute for Health and Care Excellence; 2009.

74. Saeed AM. Comparative study between trabeculectomy with photodynamic therapy (BCECF-AM) and trabeculectomy with antimetabolite (MMC) in the treatment of primary open angle glaucoma. Clin Ophthalmol. 2012;6:1651-64.

75. Matlach J, Dhillon C, Hain J, Schlunck G, Grehn F, Klink T. Trabeculectomy versus canaloplasty (TVC study) in the treatment of patients with open-angle glaucoma: a prospective randomized clinical trial. Acta Ophthalmol. 2015;93:753-61.
76. Lewis R, Reitsamer H. The Xen procedure: 1-year results of an ab-interno gelatin stent along with cataract surgery for the treatment of glaucoma. ASCRS-ASOA Symposium and Congress; 2016.

77. Rekas M, Lewczuk K, Jablonska J, Rudowicz J. Two year follow-up data with a soft and permanent, minimally-invasive ab-interno subconjunctival implant in open-angle glaucoma subjects. Eur Soc Cataract Refractive Surgeons. 2014:P291.

78. Eriksson A, Burcharth J, Rosenberg J. Animal derived products may conflict with religious patients' beliefs. BMC Med Ethics. 2013;14:48.

79. Hopes M, Broadway D. Preservative-free treatment in glaucoma is a sensible and realistic aim for the future. Eur Ophthalmic Rev. 2010;4(1):23-8.

80. Azuara-Blanco A, Katz LJ. Dysfunctional filtering blebs. Surv Ophthalmol. 1998;43:93-126.

81. Emi K, Pederson JE, Toris CB. Hydrostatic pressure of the suprachoroidal space. Invest Ophthalmol Vis Sci. 1989;30:233-8.

82. Cunliffe I. Suprachoroidal haemorrhage. Eye (Lond). 1998;12:755-6.

83. Gigon A, Shaarawy T. The suprachoroidal route in glaucoma surgery. J Curr Glaucoma Pract. 2016;10(1):13-20.

84. Ansari E. An update on implants for minimally invasive glaucoma surgery (MIGS). Ophthalmol Ther. 2017;6:1-9.

85. Chen DZ, Sng CCA. Safety and efficacy of microinvasive glaucoma surgery. J Ophthalmol. 2017; 13. Article ID 3182935. https://doi.org/10. $1155 / 2017 / 3182935$.

86. Lavia C, Dallorto L, Maule M, Ceccarelli M, Fea AM. Minimally-invasive glaucoma surgeries (MIGS) for open angle glaucoma: a systematic review and meta-analysis. PLoS One. 2017;12(8):e0183142.

87. Pillunat LE, Erb C, Junemann AG, Kimmich F. Micro-invasive glaucoma surgery (MIGS): a review of surgical procedures using stents. Clin Ophthalmol. 2017;11:1583-600.

88. Yep T, Patel V, Slejko JF, Devine B. Comparing total and disease specific healthcare costs for glaucoma patients before and after their index diagnosis: a retrospective claims database analysis. Value Health. 2015;18:A181.

89. Pasquale LR, Dolgitser $M$, Wentzloff JN, et al. Health care charges for patients with ocular hypertension or primary open-angle glaucoma. Ophthalmology. 2008;115(4):633-8. 
90. Lindblom B, Nordmann JP, Sellem E, et al. A multicentre, retrospective study of resource utilization and costs associated with glaucoma management in
France and Sweden. Acta Ophthalmol Scand. 2006;84:74-83. 